\title{
DETERMINATION OF BILIRUBIN WITH PRECIPITATION OF THE PLASMA PROTEINS
}

\author{
BY \\ E. J. KING AND R. V. COXON \\ From the Postgraduate Medical School, London
}

(RECEIVED FOR PUBLICATION JANUARY 23, 1950)

\begin{abstract}
Methods for the estimation of bilirubin are of two general types: those in which the bilirubin is caused to react with diazotized sulphanilic acid through the agency of added ethanol, which causes precipitation of the plasma proteins; and those in which some other agent is used to bring the bilirubin into reaction, without precipitating the proteins. The former methods (for example, those of van den Bergh, 1918, quoted by Thannhauser and Andersen, 1921 ; Jendrassik and Czike, 1928 ; Haslewood and King, 1937) all suffer from the disadvantage that some bilirubin may be lost in the protein precipitate. Van den Bergh recognized the difficulty, and Haslewood and King measured the loss to be about $10 \%$ in the case of highly icteric sera, but pointed out the impossibility of estimating what it might be with sera containing only small amounts of the pigment. Methods not entailing precipitation of the plasma proteins are most prominently represented by the procedures of Malloy and Evelyn (1937), Rappaport and Eichhorn (1943), and Gray and Whidborne's (1946) modification of the latter. Gray and Whidborne found an average difference of $40 \%$ between a "precipitation" method on the one hand and two "nonprecipitation" methods on the other, when these were applied to sera and plasma from cases of jaundice. Because we have been dissatisfied with the performance of the "non-precipitation" methods thus far described, for example, on account of the very pale colours produced in the Malloy and Evelyn method, which employs a very high dilution ( 1 in 25 ), and the frequently " impure" colours produced by the Rappaport and Eichhorn method, we have sought another procedure.

After trying several polyhydric alcohols (glycerol and glycols), whose hydroxyl groups were counted on to favour the retention of the plasma proteins in solution, a mixture of glycerol (35), ethanol (25), and water (25) was adopted. This furnished a favourable medium for the diazotization of bilirubin, at a 1 in 10 dilution so that the colours to be measured were reasonably intense ; and there was no tendency of the plasma proteins to precipitate. The colours obtained were indistinguishable from those produced from pure bilirubin in ethanol, and the procedure devised was quick and easy. Recovery of added bilirubin averaged nearly $100 \%$; and there was good agreement between values obtained by this "glycerol method" and the method of Malloy and Evelyn. We reported the procedure and results to the Biochemical Society (King and Coxon, 1949), but later discovered that with certain blood sera (from the cord blood of jaundiced babies) erroneously low results were obtained. These sera were highly "indirect," in the sense that the van den Bergh reaction was
\end{abstract}


very slow to develop, and the colour continued to increase for a very long time. Likewise in the "glycerol method" the bilirubin reacted slowly; the colours frequently took several hours to reach their maximum, and in several instances never attained a sufficient intensity to represent all the bilirubin known to be present. With the Malloy and Evelyn method (methanol) the colour development also seemed to be retarded somewhat, but not nearly to the same extent as it was with glycerol.

Only with ethanol in adequate concentration does the diazo reaction appear to go to completion in a reasonable time ( $<30$ minutes) ; but it is necessary to use a higher dilution of the serum and reagents in ethanol (i.e., 1 in 10 instead of the previous 1 in 4 dilution of Haslewood and King, 1937), and to allow for the bilirubin azo dye distributed through the precipitated protein, in order to obtain colours which represent all the bilirubin present. With highly icteric sera it is necessary also to dilute the sera with a buffer in order to diminish the concentration of bilirubin sufficiently to ensure that all of it will react with the diazo reagent.

The method to be described yields colours which are spectrally identical with those produced under similar conditions from pure bilirubin, gives reasonably accurate recovery of added pure bilirubin, and compares favourably in the results procured on a wide range of icteric sera with the Malloy and Evelyr. procedure. The colours are equally suitable for Duboscq and photoelectric colorimeters.

\section{Reagents}

Diazo A.-Sulphanilic acid (1 g.) dissolved in 11 . of 0.25 $\mathrm{N}-\mathrm{HCl}$.

Diazo B. $-\mathrm{NaNO}_{2} 0.5$ g. in $100 \mathrm{ml}$. water.

Protein Precipitant.-Saturated $\left(\mathrm{NH}_{4}\right)_{2} \mathrm{SO}_{4}$ solution.

Diluent.-Ethanol $85 \%$.

Phosphate Buffer Solution.$\mathrm{Na}_{2} \mathrm{HPO}_{4} \cdot 12 \mathrm{H}_{2} \mathrm{O} 3.6 \mathrm{~g}$. in $100 \mathrm{ml}$. water.

Artificial Methyl Red Standard (identical in colour with diazotized bilirubin). $-2.9 \mathrm{mg}$./l. in acetate buffer at $p H 4$ 4.63. This is made in two stages. A stock solution is prepared containing $0.29 \mathrm{~g}$. of pure methyl red (o-carboxy benzene azodimethylaniline) in $100 \mathrm{ml}$. of glacial acetic acid; $1 \mathrm{ml}$. of this stock solution is placed in a litre flask together with $5 \mathrm{ml}$. of glacial acetic acid. About $500 \mathrm{ml}$. of water are added,

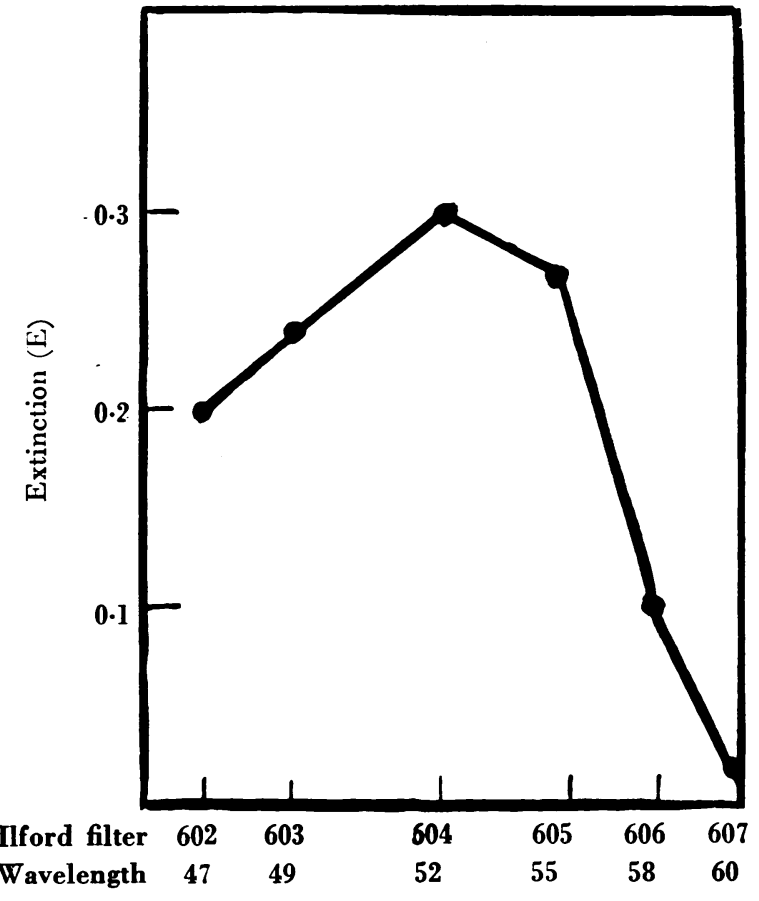

Fig. 1. Spectral absorption curve of the artificial methyl red standard used for comparison with standard bilirubin azo-dye solutions and tests prepared from blood sera with diazotized sulphanilic acid. (Spekker absorptiometer; Ilford spectrum filters; wavelength $\mathrm{c}_{\mu}$.) 


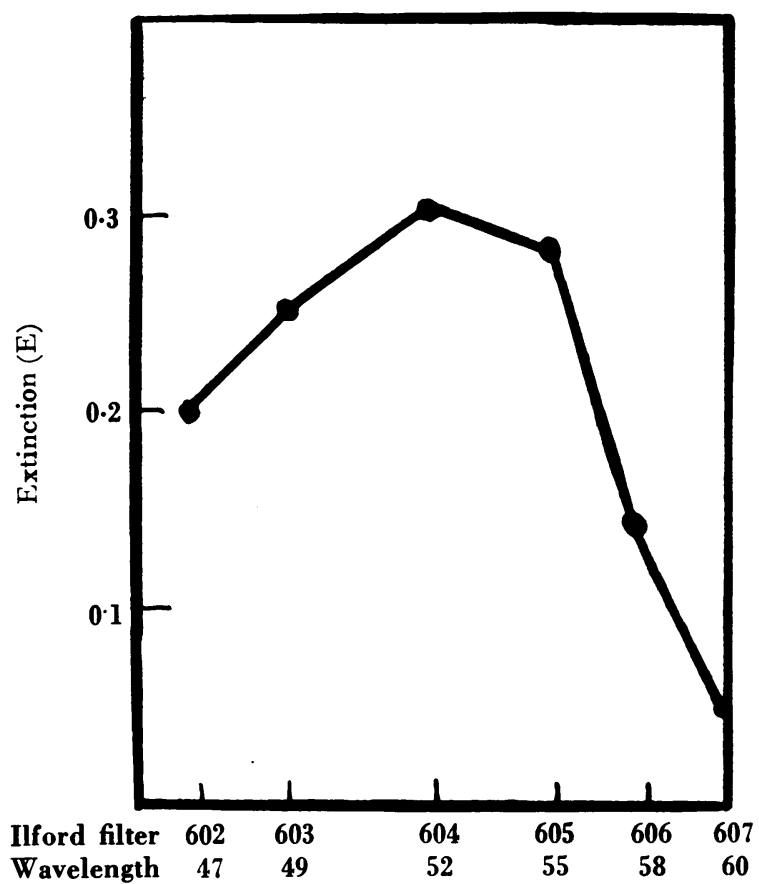

Fig. 2.-Spectral absorption curve of standard bilirubin azodye solution used. Final concentration corresponding to $0.4 \mathrm{mg}$. bilirubin $/ 100 \mathrm{ml}$. of coloured solution; equivalent to $4 \mathrm{mg}$. bilirubin $/ 100 \mathrm{ml}$. serum at a 1 in 10 dilution. followed by $14.4 \mathrm{~g}$. of crystalline sodium acetate. After the salt has dissolved, further water is added to make up the volume to $1 \mathrm{l}$. Its spectral curve is given in Fig. 1, and that of a pure bilirubin-azo-dye standard in Fig. 2.

This is the same standard as was used by Haslewood and King (1937). In that method it represented $1.6 \mathrm{mg}$. of bilirubin/100 $\mathrm{ml}$. of plasma, with the plasma at a final dilution, after diazotization and treatment with ethanol, etc., of 1 in 4 . In the present method, with a final dilution after diazotization of 1 in 10 , the standard represents $4 \mathrm{mg}$. of bilirubin $/ 100 \mathrm{ml}$.

Standard Bilirubin Solution.For testing the accuracy of the method a standard solution of bilirubin was made of $10 \mathrm{mg}$. "pure" bilirubin (East Kodak) dissolved in $100 \mathrm{ml}$. of chloroform. It was found necessary to heat the mixture gently under reflux to bring the bilirubin into solution in the chloroform.

\section{Procedure}

The volumes suggested below provide $10 \mathrm{ml}$. of test solution $(8 \mathrm{ml}$. after filtration), which is a convenient quantity for the cells of most photoelectric and Duboscq colorimeters. Smaller volumes in the same proportion may be taken, depending on the capacity of the cups of the colorimeter employed ; as little as $0.1 \mathrm{ml}$. of serum has been successfully used.

Take $1 \mathrm{ml}$. of plasma or serum in a test tube. Add $0.5 \mathrm{ml}$. of diazo reagent (when the type of van den Bergh reaction, e.g., "direct," may be noted).* Add $0.5 \mathrm{ml}$. of $\left(\mathrm{NH}_{4}\right)_{2} \mathrm{SO}_{4}$ solution and make up to $10 \mathrm{ml}$. with diluent $(85 \%$ ethanol). Mix well and stopper, and leave the solution lying horizontally with an even distribution of the precipitate for 30 minutes. Filter and then measure the extinction (optical density) of the test in a photoelectric colorimeter (or Duboscq colorimeter with a $0.5 \mathrm{D}$ grey screen, Haslewood and King, 1937), using a green light filter, and making the zero setting with water. Measure the extinction of the standard with the zero setting made with water. Direct comparison of the test with the standard solution may also be made in any type of visual colorimeter.

* An estimation of the " direct" bilirubin may be made by diluting this mixture of 1 ml. serum and $0.5 \mathrm{ml}$. diazo reagent to $10 \mathrm{ml}$. with water, and reading in the colorimeter at, e.g., 1 minute ("1 minute direct"), or at various intervals to follow the course of development of the colour. Compare the direct-indirect quotient (D.I.Q.) of Grey and Whidborne (1947). 
Calculation.-Calculations are made as follows:

Photoelectric Instruments.-When $E_{T}=$ the extinction of the azobilirubin in the test, $E_{s}=$ the extinction of the standard, and $4=$ the equivalent strength of the artificial methyl red standard in terms of $\mathrm{mg}$. bilirubin in $100 \mathrm{ml}$. of plasma:

$$
\text { mg. bilirubin } / 100 \mathrm{ml} \text {. plasma }=\frac{E_{r}}{E_{s}} \times 4 .
$$

Duboscq Colorimeters.-When $T=$ the reading in $\mathrm{mm}$. of the test, $S=$ the reading of the standard, and $4=$ the equivalent strength of the standard:

$$
\text { mg. bilirubin } / 100 \mathrm{ml} \text {. of plasma }=\frac{S}{T} \times 4 .
$$

Additional Procedure for Sera of High Bilirubin Content.-If the value of $E_{r}$ is more than twice that of $E_{s}$ (or, as $\mathrm{mg}$. of bilirubin, is greater than 8), a suitable dilution of the original serum with the phosphate buffer solution may be made (e.g, 1 in 3,1 in 10), and the procedure repeated. Since this additional step involves a dilution of the serum, (e:g., by 1 in 3), the resultant reading must, of course, be multiplied by the dilution factor to give the true concentration. Sera which are obviously icteric may be diluted in the first instance.

\section{Results}

Recoveries.-The recoveries achieved by this method, when tested on sera to which known amounts of bilirubin had been added, are shown in Table I.

TABLE I

\begin{tabular}{|c|c|c|c|c|}
\hline $\begin{array}{c}\text { Serum } \\
\text { Bilirubin } \\
\text { (mg./100 ml.) }\end{array}$ & $\begin{array}{c}\text { Bilirubin } \\
\text { Added to Serum } \\
\text { (mg./100 ml.) }\end{array}$ & $\begin{array}{c}\text { Total } \\
\text { Bilirubin Found } \\
\text { (mg./100 ml.) }\end{array}$ & $\begin{array}{l}\text { Added Bilirubin } \\
\text { Recovered } \\
\text { (mg./100 ml.) }\end{array}$ & Recovery (\%) \\
\hline $\begin{array}{r}\text { Normal sera } \\
\left\{\begin{array}{l}0.46 \\
0.41 \\
0.23 \\
0.23 \\
0.42 \\
0.42\end{array}\right.\end{array}$ & $\begin{array}{l}1.6 \\
1.6 \\
4.65 \\
4.60 \\
9.3 \\
9.7\end{array}$ & $\begin{array}{l}1.96 \\
1.91 \\
4.55 \\
4.65 \\
9.3 \\
9.4\end{array}$ & $\begin{array}{l}1.5 \\
1.5 \\
4.32 \\
4.42 \\
8.9 \\
9.0\end{array}$ & $\begin{array}{l}94 \\
94 \\
93 \\
96 \\
95 \\
93\end{array}$ \\
\hline $\begin{array}{l}\text { Undiluted sera of } \\
\left\{\begin{array}{l}8.0 \\
7.9 \\
7.6 \\
7.4\end{array}\right.\end{array}$ & $\begin{array}{c}\text { emolytic jaundice } \\
1.8 \\
1.8 \\
4.5 \\
4.5\end{array}$ & $\begin{array}{r}9.7 \\
9.7 \\
11.5 \\
10.9\end{array}$ & $\begin{array}{l}1.7 \\
1.8 \\
3.9 \\
3.5\end{array}$ & $\begin{array}{r}94 \\
100 \\
87 \\
78\end{array}$ \\
\hline $\begin{array}{l}\text { Haemolytic jaund } \\
\qquad\left\{\begin{array}{l}7.7 \\
7.5 \\
7.6 \\
7.2\end{array}\right.\end{array}$ & $\begin{array}{c}\text { serum diluted } 1 \text { to } \\
8.4 \\
7.8 \\
22.8 \\
22.6\end{array}$ & $\begin{array}{c}\text { vith buffer (results } \\
15.9 \\
15.5 \\
30.7 \\
29.8\end{array}$ & $\begin{array}{c}\text { ultiplied by 5) } \\
8.2 \\
8.0 \\
23.1 \\
22.6\end{array}$ & $\begin{array}{r}98 \\
102 \\
101 \\
100\end{array}$ \\
\hline $\begin{array}{l}\text { Obstructive jaundi } \\
\left\{\begin{array}{l}9.55 \\
9.55 \\
17.4 \\
17.6\end{array}\right.\end{array}$ & $\begin{array}{c}\text { serum diluted } 1 \text { to } 5 \\
8.65 \\
8.4 \\
21.8 \\
21.8\end{array}$ & $\begin{array}{c}\text { ith buffer (results } \\
17.7 \\
18.2 \\
39.1 \\
39.6\end{array}$ & $\begin{array}{c}\text { ultiplied by 5) } \\
8.15 \\
8.65 \\
21.7 \\
22.0\end{array}$ & $\begin{array}{r}94 \\
102 \\
100 \\
101\end{array}$ \\
\hline
\end{tabular}

Recovery of Bilirubin Added to Sera 
The technique by which these figures were obtained was as follows:

A solution was prepared to contain $10 \mathrm{mg}$. of bilirubin in $100 \mathrm{ml}$. of mixed ethanol and chloroform by evaporating $20 \mathrm{ml}$. of the bilirubin solution in chloroform on a water bath down to about $5 \mathrm{ml}$. and then making it up again to $20 \mathrm{ml}$. with absolute ethanol.

Various volumes of this ethanol-chloroform solution of bilirubin were then incorporated in mixtures of serum and diluent and then diazotized. A second set of mixtures was made up at the same time substituting phosphate buffer for serum. Each

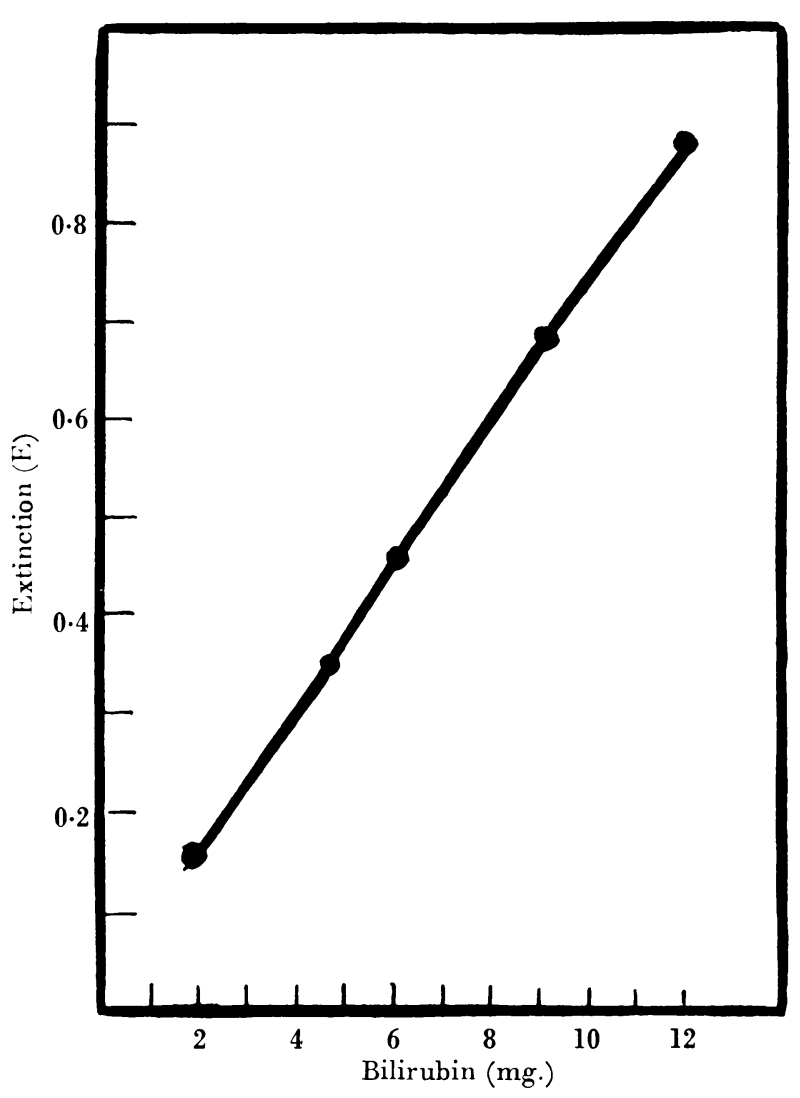

FIG. 3.-Graph of relation between colour density and concentration of bilirubin. Abscissae: $\mathrm{mg}$. of bilirubin equivalent per $100 \mathrm{ml}$. of serum; actual bilirubin present in the bilirubin azo-dye solution, 0.1 of that shown. (Spekker absorptiometer; Ilford 604 spectrum green filter.) test solution was then read, and the recovery calculated by comparing the amount added (as indicated by the bilirubin + phosphate-buffer mixture) with the amount found in the mixture containing serum, both being referred to the artificial standard. (This method of estimating recoveries obviates any inaccuracy arising from impurity of the bilirubin used and from any deterioration of the standard solution of bilirubin, its behaviour in the phosphate-containing mixture having been established in the first instance when it was freshly made up.) The straight line relationship between the amounts of bilirubin added in standard solutions and the colour development is illustrated in Fig. 3.

Relation of Colour Development to $p H$.-Using a green filter (Ilford spectrum green 604 or 624$)$, the photoelectric reading varies by approximately $5 \%$ over the range $p \mathbf{H ~} 2.9$ to 3.5. To assess the relevance of this variation to the estimation of bilirubin in plasma and serum, specimens of these fluids were pooled in batches, and samples from each batch were then put through the estimation procedure and the resulting mixtures tested by the glass electrode. All gave $p \mathrm{H}$ values within the range 3.1 to 3.4 . It may thus be inferred that the maximum error to be expected in an estimation from this source will not exceed $5 \%$.

Time Course of Diazo Reaction.-Table II gives a series of readings on the same specimen of serum at varying intervals from the time of carrying out the diazotization 
TABLE II

Colour (mg. Bilirubin/100 ml. Serum) of Bilirubin Azo-dye Test Solution from " HighLY INDIRECT" SERUM

\begin{tabular}{|c|c|c|c|c|c|c|}
\hline Filtered at & \multicolumn{6}{|c|}{ Read in Photoelectric Colorimeter at } \\
\hline $\begin{array}{l}5 \mathrm{~min} . \\
30 \mathrm{~min} . \\
1 \mathrm{hr} . \\
3 \mathrm{hr} . \\
5 \mathrm{hr} . \\
24 \mathrm{hr} .\end{array}$ & $\begin{array}{c}2 \min . \\
16.3 \\
-\end{array}$ & $\begin{array}{c}30 \mathrm{~min} . \\
15.1 \\
18.0\end{array}$ & $\begin{array}{l}1 \mathrm{hr} . \\
15.1 \\
18.0 \\
18.0\end{array}$ & $\begin{array}{l}3 \mathrm{hr} . \\
18.3 \\
17.7 \\
17.4\end{array}$ & $\begin{array}{l}5 \mathrm{hr} . \\
15.1 \\
17.7 \\
18.0 \\
17.2 \\
17.7\end{array}$ & $\begin{array}{c}24 \mathrm{hr} . \\
15.0 \\
18.9^{*} \\
19.2^{*} \\
17.7 \\
18.9^{*} \\
17.9\end{array}$ \\
\hline
\end{tabular}

* Slightly cloudy.

Eel photoelectric colorimeter and Ilford 624 bright spectrum green filter were used.

and addition of the diluent to the time of filtration. The results (which are typical of several obtained from sera giving an indirect van den Bergh reaction) show that a reading made after the reaction has been allowed to proceed for 30 minutes will give a reliable estimate of the bilirubin level, since the curve becomes horizontal beyond that point on the time scale. This conclusion was confirmed by a comparison (Table III) of the values obtained of using the present procedure and the Malloy and Evelyn (1937) method of estimation.

Necessity for Additional Dilution of Highly Icteric Samples.-It has been reported by Gray and Whidborne (1946) that proportionality between colour density and concentration of azobilirub:n ceases to hold good at high concentrations. With any method of estimation, where a natural or artificial standard is employed, it is essential, in keeping with the general principles governing colorimetric procedures, to ensure

TABLE III

\begin{tabular}{|c|c|}
\hline $\begin{array}{l}\text { Present Method (Modified Haslewood-King) } \\
\text { (mg. Bilirubin/100 ml.) }\end{array}$ & $\begin{array}{l}\text { Malloy-Evelyn Method } \\
\text { (mg. Bilirubin/100 ml.) }\end{array}$ \\
\hline $\begin{array}{r}0.2 \\
1.0 \\
1.6 \\
1.6 \\
1.6 \\
1.9 \\
2.3 \\
2.6 \\
3.4 \\
3.5 \\
3.7 \\
4.1 \\
5.0 \\
5.3 \\
8.0 \\
8.9 \\
12.7 \\
16.0 \\
26.6\end{array}$ & $\begin{array}{r}0.5 \\
1.0 \\
1.3 \\
1.5 \\
1.4 \\
1.8 \\
2.0 \\
3.0 \\
3.3 \\
3.3 \\
3.5 \\
3.2 \\
4.9 \\
4.7 \\
9.9 \\
8.2 \\
16.6 \\
16.4 \\
26.0\end{array}$ \\
\hline Average: 5.8 & 5.9 \\
\hline \multicolumn{2}{|c|}{ Root mean square of the differences: $1.1 \mathrm{mg}$. } \\
\hline
\end{tabular}


TABLE IV

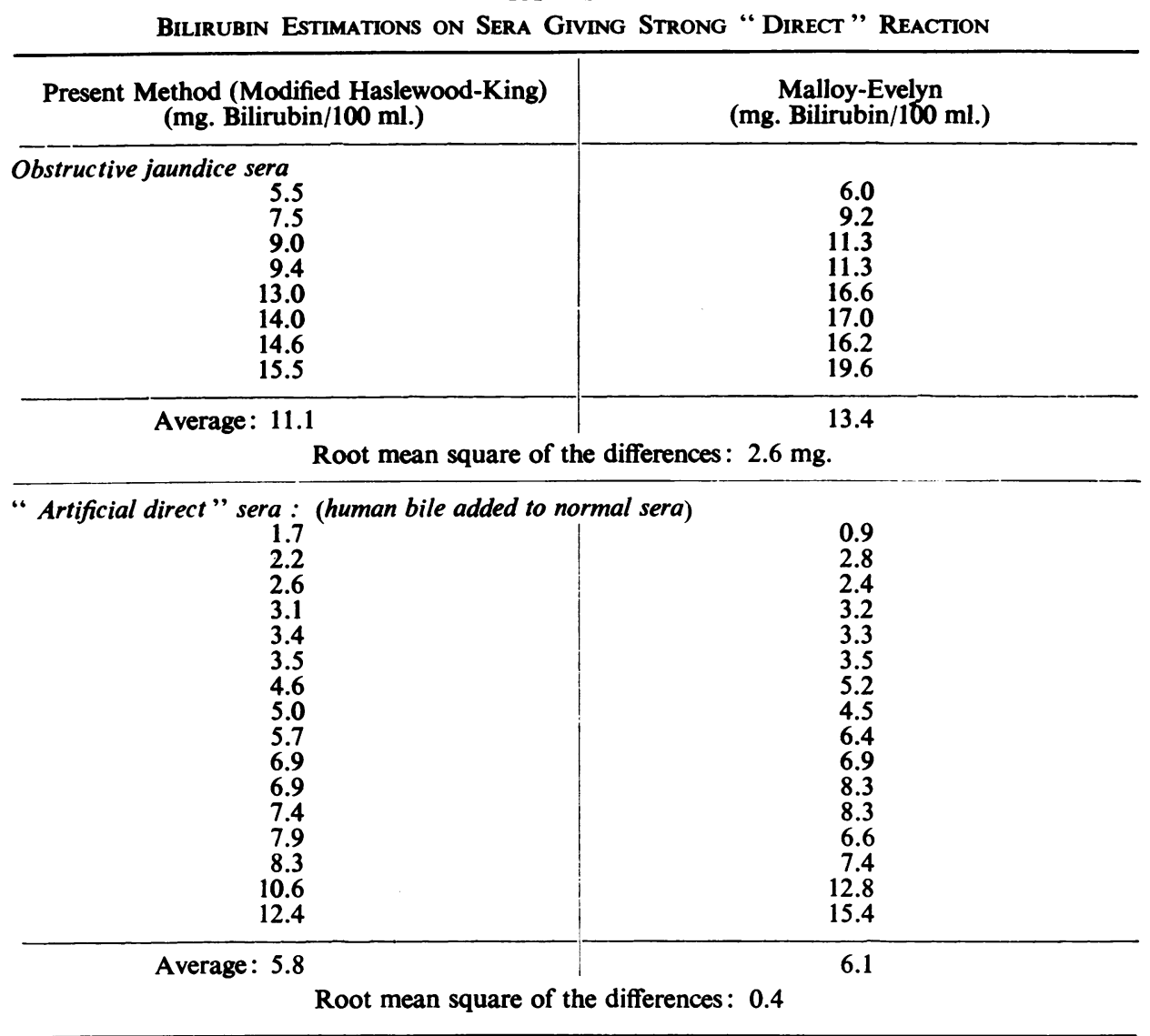

that the standard and test solution do not differ widely in concentration. Our experiments, while confirming the general conclusions of Gray and Whidborne, have demonstrated that, up to a figure which exceeds by a safe margin double that represented by the artificial standard, Beer's law is satisfactorily obeyed (Fig. 3): for this reason we have suggested this level (i.e., $8 \mathrm{mg}$. bilirubin/100 ml. plasma) as the "critical level" above which further dilution should be resorted to. This additional step can be carried out very rapidly, and with a minimum of extra trouble, by the expedient mentioned in the section dealing with the technique of the estimation. Dilution of the serum is carried out with buffer and the diluted serum treated with diazo reagent. In contrast with the experience of Gray and Whidborne, we have found evidence of incomplete coupling at high concentrations of bilirubin, and that more diazo reagent would under these conditions produce more colour. Serial dilutions as recommended here will ensure a sufficiency of the reagent for the complete conversion of all the bilirubin present into the azo dye.

The Phosphate Buffer Solution.-Some previous experiments in this laboratory (Wootton, 1946) had suggested that a $3.6 \%(\mathrm{w} / \mathrm{v})$ solution of $\mathrm{Na}_{2} \mathrm{HPO}_{4} .12 \mathrm{H}_{2} \mathrm{O}$ would, when added to Ehrlich's diazo reagent, behave as regards its buffering effect in a 
TABLE V

Bilirubin Estimations on Bile Diluted with Buffer and Blood Serum*

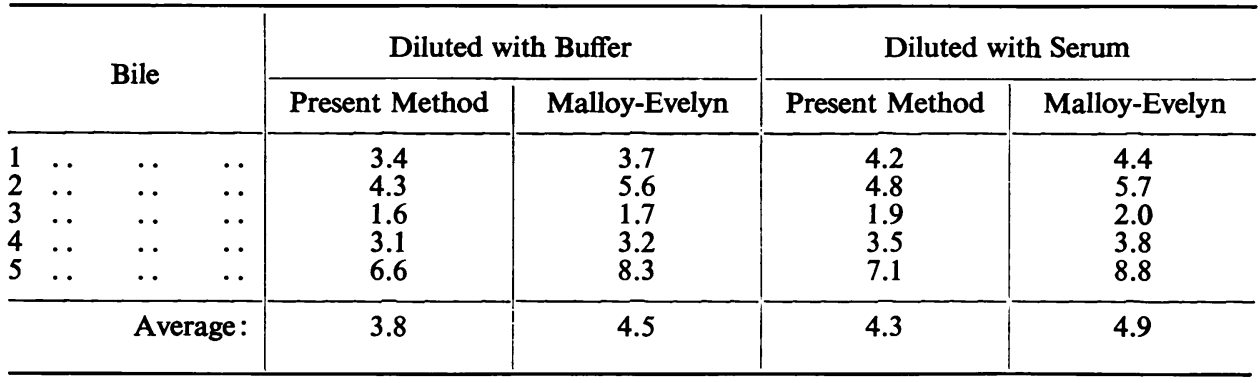

* Both mixtures gave strong " direct" van den Bergh reactions. Results expressed as mg. bilirubin/100 ml. of mixture.

TABLE VI

Bilirubin Estimations on Sera Giving “ Indirect" or " Delayed Direct" Reaction

\begin{tabular}{|c|c|}
\hline $\begin{array}{l}\text { Present Method (Modified Haslewood-King) } \\
\text { (mg. Bilirubin/100 ml.) }\end{array}$ & $\begin{array}{l}\text { Malloy-Evelyn } \\
\text { (mg. Bilirubin } / 100 \mathrm{ml} \text { ) }\end{array}$ \\
\hline $\begin{array}{l}1.1 \\
1.8 \\
2.0 \\
2.2 \\
2.9 \\
3.2 \\
3.2 \\
3.3 \\
3.7 \\
3.7 \\
4.0 \\
5.0 \\
5.3 \\
6.1 \\
6.5\end{array}$ & $\begin{array}{l}0.8 \\
2.1 \\
1.6 \\
1.7 \\
2.6 \\
3.4 \\
3.3 \\
2.5 \\
3.0 \\
3.7 \\
4.1 \\
4.2 \\
5.0 \\
4.0 \\
6.4\end{array}$ \\
\hline Average: 3.6 & 3.2 \\
\hline
\end{tabular}

Bile-stained fluid from peritoneum : " mixed" or " delayed direct" reaction

(a) Diluted with Phosphate Buffer

2.7
3.6
4.1
4.7
4.9
5.6
6.4
6.6

(b) Diluted with Serum

$$
3.9
$$$$
5.1
$$$$
5.3
$$$$
6.3
$$

3.9
5.1
5.3
6.3

Average: 4.9 
manner closely resembling serum. Confirmation of this suggestion was found in the behaviour of this buffer and of serum towards varying amounts of the diazo reagent, when similar $p \mathrm{H}$ values and similar colours were obtained in test solutions containing the same amounts of bilirubin.

Comparison of Methods. - To assess the comparative performance of the procedure put forward, a series of parallel estimations has been made on some samples of serum by the present method and that of Malloy and Evelyn (1937). In order to cover a greater range of bilirubin concentrations than could be obtained from the random use of samples obtained from routine material, a number of synthetic mixtures of bile and serum were also analysed in the same way. The results of these experiments are given in Tables III, IV, V, and VI.

\section{Discussion}

The high dilution entailed in the Malloy and Evelyn method is a considerable drawback since, with colorimeter cells of the usual $1 \mathrm{~cm}$. depth, the readings of serum bilirubin levels below $2.5 \mathrm{mg}$. bilirubin $/ 100 \mathrm{ml}$. plasma are so small as to be difficult to measure at all accurately, while the deeper cells of most instruments require more than the $10 \mathrm{ml}$. of fluid that is available from $1 \mathrm{ml}$. of plasma. With Duboscq colorimeters the difficulty of reading such pale solutions is even greater.

The Rappaport and Eichhorn method gives a considerably greater depth of colour for a given bilirubin concentration. But the colours obtained are often very different from that of the standard, and, apart from the relatively complex nature of the solutions employed, there seems to be some doubt in regard to the efficiency as well as the mode of operation of their "indirect" reagent mixture. The latter contains caffeine, citrate, and urea. Jendrassik and Czike (1928), in the course of a description of the use of caffeine sodium benzoate for potentiating the "indirect" van den Bergh reaction, state that the active component is the benzoate (which can be replaced in this connexion by salicylate), while caffeine alone, and likewise caffeinecitrate, are inert. More recently Gardikas, Kench, and Wilkinson (1947) have found that, though caffeine does exert an effect, it is a relatively slow one. This last finding would appear to be consistent with the observation of Gray and Whidborne (1946) that the "indirect" reaction, using a modified Rappaport and Eichhorn technique, tended in some instances not to proceed to completion until between six and 24 hours had elapsed. Gray and Whidborne (1947) also noted that the urea present in the Rappaport and Eichhorn buffer had some effect in promoting the diazotization of bilirubin from cases of haemolytic jaundice. These workers' (1946) results for total bilirubin estimations, by their modified Rappaport and Eichhorn method, agreed well on the whole with parallel estimations by the Malloy and Evelyn method, but the readings on the sera of patients with haemolytic jaundice were made, in the case of the former method, six hours after the preparation of the test solution.

In the method described in the present paper the final mixture contains $68 \%$ $(\mathrm{v} / \mathrm{v})$ ethanol. From our own experiments with varying strengths of ethanol and from data given by Malloy and Evelyn (1937), this concentration of ethanol is certainly sufficient to produce the maximum colour. From their context it seems that the figures given by Malloy and Evelyn were derived from experiments using methanol, but they mention elsewhere in the same publication that this was preferred to ethanol only because it gave somewhat clearer solutions, and that the 
development of colour was the same with ethyl alcohol. However this may be, we have found that when we have compared our method with that of Malloy and Evelyn, using sera from cases which gave an indirect reaction as judged by the classical van den Bergh test, the ethanol technique gave the higher results, the extinctions of the solutions being measured in both methods 30 minutes after their preparation.

The necessity for the further dilution of highly icteric sera, over and above the standard degree recommended for the method, is not peculiar to the present procedure. Malloy and Evelyn recommend diluting their final solution if above a level of about $15 \mathrm{mg}$. bilirubin/100 ml. of plasma, and Rappaport and Eichhorn also recommend further dilution of highly concentrated test solutions, without, however, specifying any particular ceiling value. Dilution in our method with an appropriate buffering fluid will establish the $p \mathrm{H}$ very near to that at which the optical density of the test solution corresponds exactly with that with which the artificial standard is calibrated, so that any error from this source, which would represent larger absolute amounts of bilirubin in the more jaundiced sera, will be minimized. Incidentally, any disturbing effect of the buffering capacity of the serum, which might result from the hypoproteinaemia which may accompany liver damage, will also be lessened.

The present method thus appears to us to possess certain definite advantages. Compared with the Malloy and Evelyn technique it entails less pipetting and also gives a stronger colour enabling more accurate estimations to be made on sera and plasma of relatively low bilirubin content. Moreover, the use of the artificial standard avoids the necessity of preparing a calibration curve with standard solutions of bilirubin, which is unavoidable with the Malloy and Evelyn method unless an Evelyn colorimeter is available. Compared with the Rappaport and Eichhorn procedure, the present method produces colours which are much nearer in quality to those obtained with pure bilirubin ; it employs reagents of simpler composition which are therefore easier to make up, and it enables readings to be taken at a much shorter interval after preparing the test solutions than must be allowed with the Rappaport and Eichhorn method in view of the findings of Gray and Whidborne.

The discrepancies shown in Table VI for the values yielded by the present method and that of Malloy and Evelyn are the very reverse of what might be anticipated. We had thought that "indirect bilirubin " might tend to be lost on the protein precipitate, and that methods which do not precipitate the proteins might be counted on to yield stronger colours. The fact that, on the contrary, they gave weaker colours seems to indicate either that not all the "indirect bilirubin " reacts in methanol, or that it reacts more slowly than it does in ethanol. Certainly the "indirect bilirubin" of jaundiced infants reacted very much more slowly in the glycerol mixture. The chemical and physical nature of the bilirubin, or bilirubins, of the plasma obviously needs further investigation; but it may well be that these differences are entirely a matter of the degree of solubility of the bilirubin in different physical states. In this connexion the work of Malloy and Lowenstein (1940) is very suggestive.

The somewhat lower values given by our method for "direct bilirubin" in the obstructive jaundice cases are perhaps even more interesting (Table IV). Here it might appear that the "direct" pigment does not react as completely in ethanol as in methanol. But we find it very difficult to believe that the coupling with diazotized 
sulphanilic acid does not go to completion. In our own experience, and in that of others, pure bilirubin and bile react promptly and completely in ethanol, and the colour production is complete in a few minutes. Likewise the bilirubin of sera from obstructive jaundice reacts promptly and no extra colour is obtained by allowing the reacting mixture to stand for a long time before filtering off the precipitated proteins: no more azo bilirubin can be extracted from the reacting mixture after several hours than after 30 minutes. However, the colour may be different, and greater, when the reaction is carried out in methanol in the Malloy and Evelyn method, than it is in ethanol, as is seen in Table V. But there is no greater discrepancy between the colour in methanol and ethanol with the bile diluted with serum, when there is a precipitate of proteins with the ethanol method than with the bile diluted with buffer when there is no precipitate; and therefore the lower result with ethanol cannot be due to loss of the coloured substance on the precipitate of serum proteins. We therefore think that the colour obtained in the reaction conducted in ethanol represents all the bilirubin present. The small amount of extra colour which seems to be obtained in methanol may be due to the methanol itself, as Moreland, O'Donnell, and Gast (1950) found that diazotized bilirubin developed more colour in methanol than in ethanol, or to the presence of a substance other than bilirubin (e.g., bile salts; compare Thannhauser et al., 1921), which may increase the colour given by bilirubin, or may modify its quality as, indeed, often appears to be the case with the Malloy and Evelyn method where red colours with a slight bluish tint are not infrequently obtained. We hope to look for evidence on these matters by careful spectrophotometric measurements of the yellow sera from the several types of jaundice in which we have found these differences, and of the red colours they yield with the diazo reagents.

The artificial standard solution of methyl red in acetate buffer has seemed in our hands to be both the most convenient and the most reliable standard for bilirubin determinations that has been proposed. Methyl red can be obtained from almost any manufacturer of fine chemicals in a high state of purity, and it is not necessary to re-establish the relation of its colour to that of a standard prepared from pure bilirubin. All the methyl reds we have tested haye yielded the same colour and have not differed from our best bilirubin standard prepared from a specimen given us by the late Professor Hans Fischer. On the other hand, the samples of so-called "pure" bilirubin which we have purchased from commercial sources have all appeared impure by reference to the Fischer bilirubin and to the methyl red standard. The bilirubins commonly used for calibrating photoelectric instruments have in our hands all appeared to be 4 to $7 \%$ impure, and results for serum bilirubin obtained by reference to such calibrations cannot be as accurate as those from comparison with the methyl red standard. For those who prefer to use a calibrated instrument with a standard graph or chart the methyl red standard furnishes an easy means for periodic checking of the standardization.

\section{Summary}

The Haslewood and King bilirubin method has been modified to yield results which are believed to represent the true bilirubin content of blood sera with a reasonable degree of accuracy. 
Diazotization, coupling of the bilirubin, and precipitation of the proteins with ammonium sulphate and ethanol are performed as in the previous method; but the reaction is carried out at a higher dilution (1 in 10 instead of 1 in 4) and the azobilirubin contained in the precipitate of proteins is included in the calculation. High bilirubin sera are diluted with buffer before diazotization in order that the final colour produced in the method may be nearly equal to that of the standard.

The coloured test solutions obtained appear to be identical with those produced from pure bilirubin. The "impure" colours frequently obtained in non-precipitation procedures are not encountered with this method.

Bilirubin added to blood sera was recovered in the method with the usual error of about $5 \%$ common to most colorimetric analyses.

Results with "indirect" sera were, on the average, somewhat higher than those obtained in parallel estimations by the Malloy and Evelyn method.

With "direct" sera from cases of obstructive jaundice somewhat lower results were obtained.

With miscellaneous sera from cases of a wide variety of clinical conditions the overall agreement was good.

Our thanks are due to Miss L. A. Ross and Mrs. M. Levine for their valuable assistance in carrying out these experiments.

\section{REFERENCES}

Gardikas, C., Kench, J. E., and Wilkinson, J. F. (1947). Nature, Lond., 159, 842.

Gray, C. H., and Whidborne, J. (1946). Biochem. J., 40, 81. (1947). Ibid., 41, 155.

Haslewood, G. A. D., and King, E. J. (1937). Ibid., 31, 920.

Jendrassik, L., and Czike, A. (1928). Z. ges. exp. Med., 60, 554.

King, E. J., and Coxon, R. V. (1949). Biochem. J., 44, viii.

Malloy, H. T., and Evelyn, K. A. (1937). J. biol. Chem., 119, 481.

and Lowenstein, L. (1940). Canad. med. Ass. J., 42, 122.

Moreland, F. B., O'Donnell, W. W., and Gast, J. H. (1950). Fed. Proc., 9, pt. 1, 207.

Rappaport, F., and Eichhorn, F. (1943). Lancet, 1, 62.

Thannhauser, J. S., and Andersen, E. (1921). Dtsch. Arch. klin. Med., 137, 179.

van den Bergh, A. A. H. (1918). Der Gallenfarbstoff im Blute. Leipzig. Quoted by Thannhauser and Andersen (1921).

Wootton, I. D. P. (1946). Unpublished. 